\title{
Novas tecnologias em tempos pós-modernos
}

\section{RESUMO}

O estudo pretende compreender este momento presente onde a técno-socialidade comunicativa se faz sentir em diversos setores de nossas sociedades contemporâneas. O processo de vivência cotidiana, tanto real como virtual, induz a mudanças sociais significativas. A sociologia compreensiva nos permite levar em consideração os nós pontuais da complexidade nas comunicações.

\section{PALAVRAS-CHAVE}

tecno-socialidade

sociologia compreensiva

nova tecnologia em comunicação

\section{ABSTRACT}

This study aims at understanding the current moment in which communicative techno-sociability is present in several sectors of contemporary societies. The process of quotidian life, both real and virtual, leads to significant social changes. Comprehensive sociology allows us to take into consideration the core complexity difficulties of communications.

\section{KEY WORDS}

techno-sociability

comprehensive socialogy

new technologies in communication

\section{Rosa Lucila Fernandes Y Freitas}

UEL

rlucila@hotmail.com
Na modernidade ao tempo presente, as sociedades conheceram uma imensa quantidade de invenções técnicas e de evoluções tecnológicas que contribuíram para mudanças importantes nos domínios sócio-político, cultural, educacional e econômico. Depois de Gutemberg, as trocas comunicacionais eliminaram as questões têmporo-espaciais. Não existem mais barreiras geográficas para as comunicações. O tempo torna-se tempo-real nas comunicações radiofônicas, telefônicas, televisivas ou telemáticas.

As imagens, com perfeição cinematográfica de alta definição difundem-se pela televisão, pela Internet ou pelos telefones celulares por meio de satélites e fibras óticas. Em 1997, vários laboratórios já iniciavam pesquisas sobre a "fibra negra" acelerando os progressos da função de transmissão bruta de dados. A fibra negra é "um canal ótico do qual um único fio, tão fino como um fio de cabelo, poderia conter todo o fluxo de mensagens telefônicas dos Estados Unidos no Dia das Mães (data em que há o maior fluxo na rede)" (Levy, 1997, p. 35) ${ }^{1}$.

O ser humano adquiriu uma série de próteses que McLuham (1969) ${ }^{2}$ neste estudo chamou de "extensões do homem". Um exemplo dessas "máquinas-próteses" é o telefone: aparato que "provoca uma prolongação do ouvido e da voz e que forma uma espécie de percepção extra-sensorial" (McLuhan, 1969, p. 299)33. Assim, McLuhan (1969) vê o computador como uma prolongação do sistema nervoso central.

Observa também que "os meios como extensões de nossos sentidos, estabelecem novos índices relacionais, não apenas entre nossos sentidos particulares, como também entre si, na medida em que se inter-relacionam" (McLuhan, 1969, p 72) ${ }^{4}$.

Desses novos índices relacionais destacam-se, atualmente, nas novas tecnologias, a interatividade que ressalta a participação ativa de locutores e receptores de informações. No entanto, os veículos de comunicação de massa aderem à nova tecnologia para interagir com seus receptores. Podemos dizer que nesse mar de novas invenções tecnológicas a Arte e a Criatividade de uns e a Competência e o Poder de outros se entrelaçam para dar os títulos de nobreza à palavra grega "tekhné", que significa: a arte, a profissão e o processo. Nesse conjunto de possibilidades surge a tecno-socialidade (Freitas, 1997) ${ }^{5}$.

Tecno-socialidade, de certa maneira, pode designar as novas formas de interações sociais, propiciadas pelas novas tecnologias, que aparecem por todo o mundo em todos os lugares, diversificando as artes, os modos de agir, as profissões e os processos em nossa vivência cotidiana tanto real como virtual.

Esse processo progressivo está presente em todo lugar e, como uma revolução, invade nosso planeta. 
Ichbiah (Ichbiah , 1994, p. 9) ${ }^{6}$, falando da revolução multimídia nos alerta:

Apertem os cintos! A revolução multimídia está a caminho.Que queiramos ou não. Não é nem uma questão de querer ignorá-la porque a avalanche é tal que ela vai levar tudo sob sua passagem. Assim como a revolução industrial do século XIX levou a uma mudança maior na organização de nossas sociedades, nós nos aproximamos de uma mudança crucial. Ninguém pode se permitir de errá-la: aqueles que a errarem tomarão 50 anos de atraso num espaço de 10 anos. É necessário, então, nadar a favor da correnteza.

Já estamos em 2007! Estamos no "Presente 2007"! Antes de falar das transformações e das mudanças sociais induzidas pelas novas tecnologias nas comunicações é necessário refletir, um instante, sobre o mistério das expressões: "espírito do tempo" (Morin, 1983) e "momento presente" (Maffesoli, 1990)

Pensando na realidade do "aqui e agora", percebe-se que apreender o Presente não é uma missão muito simples. A priori, pode-se dizer que o momento presente existe somente por uma indecifrável e mínima porção do instante que foge.

A análise filosófica de Santo Agostinho (Santo Agostinho, 1964, p. 269) ${ }^{8}$ distingue três concepções do tempo presente:

Existem três tempos: o presente do passado, presente do presente, o presente do futuro. Porque esses três tipos de tempo existem no nosso espírito eu não os vejo em outra parte. O presente do passado, é a memória; o presente do presente, é a intuição direta; o presente do futuro é a espera.

O presente é esse instante fugidio, essa ínfima fronteira que separa o que está se passando do que já está sendo vivido. O presente absorve toda uma complexidade temporal. Assim, compreendemos o presente como o momento que contém o passado, e o futuro um tempo que se tornará presente nas lembranças do passado. Se a essa reflexão filosófica juntarmos a velocidade das mudanças que alteram uma infinidade de conceitos sociais poderemos imaginar quanto significa a complexidade do estudo de nossa vida cotidiana no presente.

Se nos detivermos a pensar no presente, a pensar o presente, e desejar compreender as mudanças que se esboçam hoje em dia, convém reconhecer ao gênio coletivo suas letras de nobreza. É a esse preço que os diferentes aspectos da vida social não mais o senso, naquilo que há de unívoco, intangível, universal: progressos, evolucionismo históricos, estados de direito nacional ou internacional, mas suas diversas significações: significações vividas com outros, e que são causas e efeitos de uma nova maneira de estar junto (Maffesoli, 1993, p. 27) ${ }^{9}$.

Para melhor compreender a complexidade da vida cotidiana, esse "estar junto com" (Mafessoli, 1993) ${ }^{10}$ mesmo que seja virtualmente, em co-presença desencarnada ou co-presença do face a face, evidencia-se essa complexidade nos múltiplos fatores da vida social que devem ser melhor analisados na sociedade informatizada e globalizada.

O melhor, neste estudo, não significa de maneira alguma o modo mais fácil. A postura proposta pela sociologia compreensiva permite levar em consideração os nós pontuais da complexidade da vida cotidiana.

“A complexidade não é tudo, não é a totalidade do real, mas é o que pode da melhor maneira, se abrir ao inteligível e revelar o inexplicável" (Morin, 1994, p. $331)^{11}$. E quando se questiona como Morin (Morin, 1994, p. 331) ${ }^{12}$ encontrou o sentido dessa reflexão, a resposta é clara:

Eu tenho a impressão que meu senso de complexidade surgiu quase instintivamente do meu senso de contradição, do meu sentido de incerteza, do meu sentido de tempo, das evoluções, da história, dos acontecimentos dos acidentes e bifurcações, da auto-observação, do meu sentido da multiplicidade da minha repugnância aos maquineísmos, e isso em todos os terrenos, filosófico, científico, político e, claro, da vida cotidiana.

O tempo, as contradições e as incertezas estão sempre presentes na busca do saber. A vida cotidiana, do ponto de vista do senso comum, faz pensar em coisas simples e na rotina banal de todos os dias. Mas, paradoxalmente, a vida traz para o dia a dia, toda a complexidade dos movimentos do tempo-presente, da história e da memória, as mais recentes descobertas científicas, os desenvolvimentos tecnológicos da atualidade, e todas as modificações importantes da vida em sociedade. Tudo isso bem camuflado na simplicidade que envolve a grande complexidade das relações humanas.

Nessa complexidade, incluí-se, não apenas a realidade concreta que não pode ser compreendida sem o encadeamento associativo das representações sígnicas e simbólicas dessa mesma realidade, e suas implicações na vida imaginária, nos sonhos, nos sentimentos, nas emoções e fantasias. Nesta contemporaneidade, assinala-se a importância das ilusões, dos simulacros e da virtualidade.

Para entender esse momento presente e a tecnosocialidade, se faz necessário considerar as recentes invenções tecnológicas que interferem seja no trabalho, nas organizações, na vida social, política e econômica, e na vida privada, nas relações familiares, amicais ou amorosas.

Autores como Kalogeropoulos e Laramée (1995, 
p.159) ${ }^{13}$ escrevem sobre o que chamam de um tempo de explosão de invenções e sobre as conseqüências que essas descobertas tem nas relações sociais. Tais autores deram enfoque à análise de um mercado potencial da realidade virtual, observando que a multimídia está se impondo como a maior revolução tecnológica do final do século XX. Neste sentido, afirmam:

A invenção da imprensa, as da rádio e da televisão fazem parte da nossa história; mas nós vivemos agora, o tempo de uma explosão de invenções que vão transformar a vida dos homens e das relações entre eles, tão certamente, mas mais rapidamente que o fizeram as de Gutemberg e as de Marconi.

Quanto aos acontecimentos passados, vale resgatar o que Castells (Castells, 2003) ${ }^{14}$ afirma que começam a se gestar no final da década de 60 até princípio da década de 80 , convergindo hoje para a "gênese de um novo mundo".

A revolução das tecnologias da informação/comunicação atua remodelando as bases materiais da sociedade e induzindo a emergência do informacionalismo como a base material de uma nova sociedade. Nesse sentido, ela tem uma importância igual ou maior à da Revolução Industrial. As novas tecnologias telecomunicacionais tornam-se as ferramentas indispensáveis na geração de riquezas, no exercício do poder e na criação de códigos culturais. No entanto, adquire particular importância ao potencializar as redes - na verdade, velhas formas de organização social - para se tornarem o modo prevalecente de organização das atividades humanas, transformando a partir de sua lógica, todos os domínios da vida social e econômica (Castells, 2003) ${ }^{15}$.

Nesta ótica, Kalogeropoulos et Laramée (Kalogeropoulos et Laramée, 1995, p. 7 $7{ }^{16}$ mostraram a necessidade de "estudar e conhecer melhor as utilizações possíveis e certos desafios dessas tecnologias que vão aumentar nossos poderes em proporções até agora desconhecidas pela humanidade". Esses autores observaram ainda, que este á apenas o início dessa "formidável mutação sem saber como dominar os seus efeitos".

A tecno-socialidade, portanto, é uma realidade em contínua transformação, onde a iniciativa, a criatividade e a inovação apresentam-se como importantes e indispensáveis requisitos da vida cotidiana neste terceiro milênio. Tal realidade tornou-se o fator primordial de motivação, para este estudo.

Realmente, a velocidade das novas invenções tecnológicas traz novidades incríveis, tais como as que se encontram na Internet em "Notícias Veiculadas em 2005" do jornal Estadão:

A Nippon Telegraph and Ttelephone Corporation de-
senvolveu um chamado RedTacton, que usa os cam-
pos elétricos existentes na pele humana para trans-
mitir dados à alta velocidade. Toshiaki Asahi,
pesquisador da NTT afirma que um casal pode
trocar arquivos de músicas e vídeos enquanto dan- ça ou faz sexo, se estiver munido do dispositivo chamado RedTacton que aproveita os campos elétricos do corpo humano para essas transmissões (Jornal Estadão, 23 março, 2005) ${ }^{17}$.

Diante disso, pode-se considerar que a ficção holiudiana torna-se realidade? Uma conseqüência melhorativa ou pejorativa das invenções e/ou aperfeiçoamentos das tecnologias?

Embora sejam notáveis os novos rumos da tecnologia, acompanhar os últimos acontecimentos dessas invenções e descobertas é pretensão absurda pela velocidade existente nesse campo. A diversidade de setores que implantaram modificações em suas estruturas em função das novas descobertas tecnológicas é enorme.

Toda nova descoberta da ciência apresenta aspectos positivos e negativos. Sabemos desde há muito tempo que existem objetivos precisos nos trabalhos científicos, mas descobrimos mais tarde que tais objetivos mesmo sendo alcançados podem induzir a outros também, desejados ou não. O caso da pílula anticoncepcional que foi criada para fertilização e concepção humana derivou o que hoje conhecemos como um eficiente e difundido método anticoncepcional.

Resultado positivo ou negativo da descoberta? Para a religião católica: pejorativo!

O desvio do resultado foi melhorativo tanto para a ciência médica como para uma grande maioria de pessoas do sexo feminino e masculino no controle da natalidade. A revolução sexual que libertou a mulher teve início com esse desvio de objetivo dos efeitos esperados.

Outro exemplo, que já estudamos em nossa tese de doutorado, foi a criação do Minitel na França - produto da telemática francesa, similar a um micro computador (composto de monitor, teclado e modem, possibilitando, portanto, diálogos à distância em tempo real ou envio de fax), com um número menor de funções para a elaboração dos textos escritos ou envio de imagens.

Inicialmente criado para economia de papel, com a utilização do anuário telefônico virtual, transformou-se no que conhecemos como um meio de comunicação semelhante à Internet. O Minitel para informações, pesquisas, reservas de livros em bibliotecas de qualquer cidade francesa, compras, pagamentos (com segurança absoluta) e o "Minitel Rose", criado pelos usuários da comunicação convivial (amical ou amorosa) ou relacionamentos sexuais virtuais nos reseaux (sites) diferenciados para homo e heterossexuais. Embora o preço das comunicações fosse considerado alto (em média 2.000 dólares para usuários assíduos, em 1993), pudemos constatar que a procura de contatos com desconhecidos no "Minitel Rose", até 1997, era bastante elevada. A mudança de conduta dos franceses foi bastante expressiva com o advento da comunicação virtual no Minitel.

Para citar mais um exemplo telecomunicacional, a própria Internet, criada para utilização exclusiva de mi- 
litares americanos (e suas estratégias secretas), se expandiu pelo mundo todo com possibilidades incontáveis no que diz respeito às interações e/ou telecomunicações, e (paradoxalmente!) a rápida (muito rápida!) difusão das mesmas. Pensar hoje em segredo militar na Internet é entender perfeitamente os paradoxos, desvios e contradições das novas invenções tecnológicas.

Se toda nova tecnologia apresenta resultados surpreendentes, nos perguntamos neste trabalho:

Quais são os aspectos positivos e negativos em nossa vida do dia a dia, em função das mudanças causadas pelas descobertas tecnológicas, e adotadas nos mais diversos setores?

Um novo modo de vida se impõe? Uma nova cultura se estabelece?

As comunicações se diferenciam desde a infância nos pequenos cidadãos que nascem já na era da informática.

O conflito de gerações sofre o impacto de todas essas mudanças em velocidade crescente. A velocidade desse "motor" que, segundo Juremir Machado da Silva (Silva, 2006, p. 12) ${ }^{18}$, é o imaginário, "o acelerador que imprime velocidade à possibilidade de ação. O homem age (concretiza) porque está mergulhado em correntes imaginárias que o empurram contra ou a favor dos ventos".

Como mencionamos no início deste texto, Ichbiah afirma que é necessário nadar a favor da correnteza para não ter em 10 anos, 50 anos de atraso. E Juremir tem razões para afirmar que, ainda hoje, com todos os avanços tecnológicos alguns imaginários empurram contra os ventos.

Poderíamos chamar de "geração digital", às crianças deste presente, com toda liberdade que lhes atribui as novas escolas psicológicas, com os direitos que lhes dá os estatutos de proteção à infância, com esse novo estilo de educação familiar (pais e mães ausentes em função do trabalho) e, formação acadêmica com recursos (quase) sempre inovados. O que pensar desses imaginários em ação? E as conseqüências positivas e negativas das novas invenções tecnológicas? Evento futuro não se pode prever, mas os imaginários da mais nova geração continuarão em ritmo de Fórmula 1 famecos

\section{REFERÊNCIAS}

LEVY, P. Cibercultura. São Paulo: Editora 34, 1999.

McLUHAN, M. Os meios de comunicação como extensões do homem. São Paulo: Cultrix, 1969.

.Os meios de comunicação como extensões do homem. São Paulo: Cultrix, 1969.

Os meios de comunicação como extensões do homem. São Paulo: Cultrix, 1969.

FREITAS, R. L. L'inconnu et l'imaginaire sur les résaux de télécommunication: téléphone, minitel et internet.
Paris, 1997. Tese (Doutorado em Sociologia) Universidade de Sorbonne - Paris V, Paris.

ICHBIAH, D. La convivialité. Paris : Éditions du Seuil, 1973.

MAFFESOLI, M. Aux creux des apparences: Pour une éthique de de l'esthétique, Paris: Ed. Plon, Le livre de poche, 1990.

SAINT Augustin. Confessions. Trad. Joseph Trabuco. Paris: Éditions Flammarion, 1964.

MAFFESOLI, M. Comtemplation du monde: Figures $d u$ style communautaire. Paris: Éditions Grasset, 1993.

_. Comtemplation du monde: Figures du style communautaire. Paris: Éditions Grasset, 1993.

MORIN, E. L'Esprit du temps. Paris: Editions Grasset, 1983.

Mes démons. Paris: Éditions Au vif/Stock, 1994.

KALOGEROPOULOS, L. ; LARAMÉE, A. Multimédia et autoroutes de l'information, Paris, Ed. Nathan, 1995.

CASTELLS, M. A sociedade em rede: a Era da Informação: economia, sociedade e cultura. $6^{\text {a }}$ ed. São Paulo: Paz e Terra, 2003, v.1.

KALOGEROPOULOS, L. ; LARAMÉE, A. Multimédia et autoroutes de l'information, Paris, Ed. Nathan, 1995.

BRASIL. MINISTÉRIO DA CIÊNCIA E TECNOLOGIA. Notícias veiculadas em Novas Tecnologias. MCT, TI, Agência@CT. Notícias veiculadas em 2005. O Estadão de São Paulo, 23 mar. 2005. Disponível em http:/ / www.mct.gov.br/ Temas/ info/ /imprensa/ Notícias 5Novas. 5.htm. Acesso em 14/12/2005.

SILVA, Juremir Machado. As tecnologias do imaginário. Porto Alegre, $2^{a}$ ed. Sulina, 2006. 